
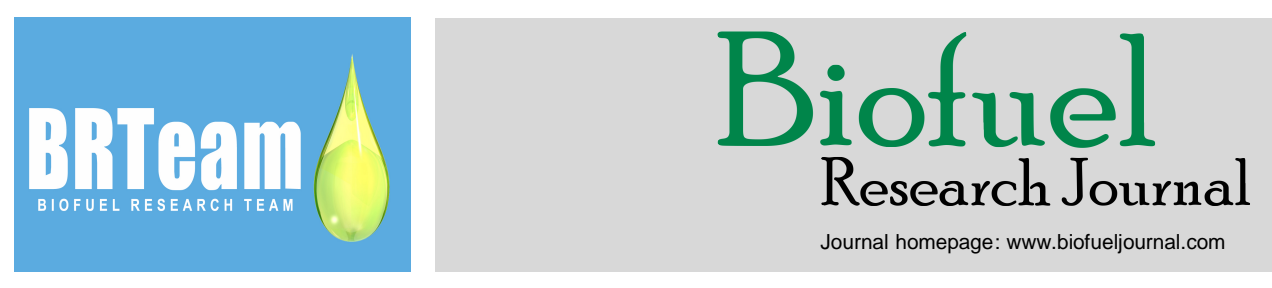

Original Research Paper

\title{
Improved lipid and biomass productivities in Chlorella vulgaris by differing the inoculation medium from the production medium
}

\author{
Shahrbanoo Hamedi, Mahmood A. Mahdavi*, Reza Gheshlaghi
}

Department of Chemical Engineering, Ferdowsi University of Mashhad, Azadi Square, Pardis Campus, 91779-48944, Mashhad, Iran.

\section{HIGHLIGHTS}

$>$ Using different media for inoculums preparation and microalgae production improved lipid and biomass productivities.

$>$ When SH4 was selected for inoculation medium and N8 was selected for production medium, $130 \%$ increase in biomass productivity and $40 \%$ increase in lipid productivity was observed. $>$ Specific growth rate improved by differing inoculums preparation medium from production medium and changed from $0.0040 / \mathrm{h}$ to $0.0122 / \mathrm{h}$.

\section{ARTICLE INFO}

\section{Article history:}

Received 15 October 2015

Received in revised form 19 March 2016

Accepted 9 April 2016

Available online 1 June 2016

\section{Keywords:}

Microalgae

Biomass productivity

Lipid productivity

Production medium

Inoculation medium

Chlorella vulgaris

\section{GRAPHICAL ABSTRACT}

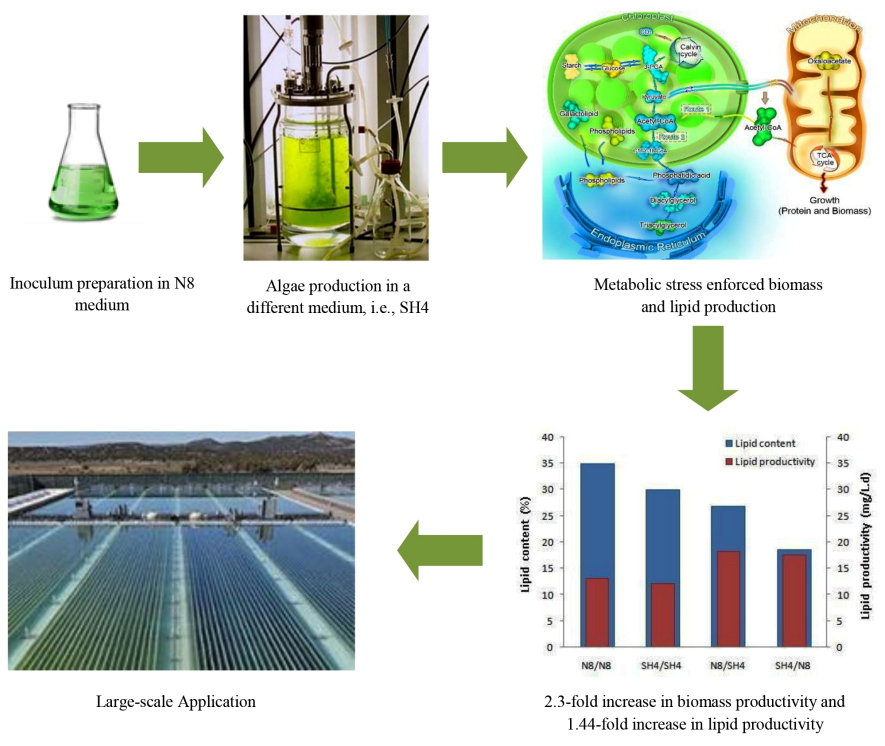

\begin{abstract}
Improvement of biomass and lipid productivities is now one of the main concerns in commercialization of microalgae cultivation as a feedstock for algal biofuel production. Conventional photoautotrophic processes using well-studied and rich in oil strain of Chlorella vulgaris are not able to meet such demands. A new strategy of inoculating algae production medium with cells grown in a different medium from the production medium was proposed herein. More specifically, when SH4 was used as production medium and N8 was used as inoculation medium, biomass and lipid productivities increased by 2.33 folds and 1.44 folds, respectively, compared with when the production and inoculation media were the same, such as SH4. The findings of the present investigation showed that this cultivation scheme resulted in $52 \%$ increase in cell number and $54 \%$ increase in dry weight leading to improved productivities. Although by even considering this improvement, photoautotrophic cultivation of algae can hardly compete with the heterotrophic cultivation, the high cost of hydrocarbon supply required in large-scale heterotrophic processes marks the technique proposed in the present study as a promising approach for commercialization of algal biofuel production.
\end{abstract}

* Corresponding author at: Tel.: +98-513-8805008 E-mail address: mahdavi@um.ac.ir

Please cite this article as: Hamedi S., Mahdavi M.A., Gheshlaghi R. Improved lipid and biomass productivities in Chlorella vulgaris by differing inoculation medium from production medium. Biofuel Research Journal 10 (2016) 410-416. DOI: 10.18331/BRJ2016.3.2.6 


\section{Introduction}

Microalgae has been at the center of attention during the past decades for its potential as a source of feedstock for biofuel production (Razon and Raymond, 2011) as well as other industrial applications (Carlsson et al., 2007). With the growing concern over carbon dioxide emission, sensible effects of global warming, and shortage of fossil fuel resources, this potential has been taken into serious consideration by governments and policy making agencies investing millions of dollars for research on commercialization of this technology (Sheehan et al., 1998). However, the feasibility of this technology as a future source of energy at a global scale requires significant increases to be achieved in algal productivity in order to generate sufficient feedstock to meet the increasing demands (US DOE, 2010).

Both biomass and lipid productivities are species-dependent at the first glance. However, environmental factors such as substrate type, nitrogen content of the media, metal elements, illumination scheme, cultivation strategy, and photobioreactor configuration could also influence the final productivities to a high extent. Numerous efforts have been reported on enhancement of biomass and lipid productivities through adjustment of these environmental factors (Mata et al., 2010; Pittman et al., 2011).

Changing environmental factors imply a "two-stage" cultivation in which conventional culture is perturbed by means of different strategies including nitrogen depletion, intense illumination, elemental supplements, etc; and consequently lipid accumulation in algal cells is stimulated under stress conditions. This approach has been adopted in many studies to improve lipid and biomass productivities. Total fatty acid was reported to increase from $86.2 \mathrm{mg} / \mathrm{g}$ cell to $137 \mathrm{mg} / \mathrm{g}$ cell in a 6-day batch culture when nitrogen content was reduced to $3 \%$ of dry weight (Richardson et al., 1969). Lownitrogen media contributed to an overall increase in lipid content from $6 \%$ to $62 \%$ in different studies (Illman et al., 2000; Hu and Gao, 2006; Converti et al., 2009; Nigam et al., 2011; Uslu et al., 2011) while lipid productivity improved from $6 \mathrm{mg} / \mathrm{L} . \mathrm{d}$ to $8 \mathrm{mg} / \mathrm{L} . \mathrm{d}$ (Widjaja et al., 2009). In a two-stage marine microalgae cultivation, transferring from $\mathrm{N}$-replete medium to $\mathrm{N}$-free medium caused lipid content to increase to $20-26 \%$ due to metabolic stress (Jiang et al., 2012). Although continuous illumination increased algal cell concentration by $25 \%$ on average (Lee and Lee, 2001; Yusof et al., 2011) with no significant differences caused by the type of illumination source, changing light intensity from $100 \mu \mathrm{E} / \mathrm{m}^{2}$.s to $200 \mu \mathrm{E} / \mathrm{m}^{2}$.s under $15: 9$ lightdark cycles contributed to $50 \%$ increase in cell density from $0.8 \times 10^{7}$ cell $/ \mathrm{mL}$ to $1.2 \times 10^{7} \mathrm{cell} / \mathrm{mL}$ (Tang et al., 2011). Controlled conditions at $60 \mu \mathrm{mol}$ photons $/ \mathrm{m}^{2}$.s along with other parameters led to a biomass productivity of 40 $\mathrm{mg} / \mathrm{L} . \mathrm{d}$ ( $\mathrm{Lv}$ et al., 2010). Optimization of media in terms of major components such as metal elements (Mandalam and Palsson, 1998), and specifically iron (Liu et al., 2008), potassium, and magnesium (Tran et al., 2010 ) increased lipid content to $56.6 \%$ and lipid and biomass productivities to $190 \mathrm{mg} / \mathrm{L} . \mathrm{d}$ and $304 \mathrm{mg} / \mathrm{L} . \mathrm{d}$; respectively. In a recent study, medium optimization resulted in high lipid content of $59.6 \%$ and lipid productivity of $74 \mathrm{mg} / \mathrm{L} . \mathrm{d}$ obtained under $750 \mathrm{mg} / \mathrm{L}$ nitrogen content and zero phosphorous content while iron was supplemented as well (Singh et al., 2015). Sufficient phosphorous concentration under nitrogen limitation condition could improve biomass production as high as nitrogen sufficient conditions (Chu et al., 2013).

Another aspect of the two-stage cultivation is switching from photoautotrophic algal growth to heterotrophic growth. The first studies on heterotrophic algal growth, with $10 \mathrm{~g} / \mathrm{L}$ glucose supply, reported an increase in lipid content of Chlorella protothecoides from 15\% to 55\% (Miao and Wu, 2006). Under three organic carbon sources including glucose $(1 \% \mathrm{w} / \mathrm{v})$, acetate $(1 \% \mathrm{w} / \mathrm{v})$, and glycerol $(1 \% \mathrm{w} / \mathrm{v}), C$. vulgaris achieved biomass productivity of $254 \mathrm{mg} / \mathrm{L} . \mathrm{d}$ and lipid productivity of $54 \mathrm{mg} / \mathrm{L} . \mathrm{d}$ on glucose with light (mixotrophic) which was 19 folds and 14 folds higher than biomass and lipid productivities obtained in the same culture with merely air bubbling into the medium, respectively (Liang et al., 2009). However, lipid content decreased from $38 \%$ to $21 \%$ at the same condition. In another attempt on heterotrophic algal production, C. vulgaris was grown heterotrophically to reach higher cell densities, and then was diluted and subjected to a light environment for photoinduction. Using this strategy, after $12 \mathrm{~h}$ of illumination, biomass productivity reached $3333 \mathrm{mg} / \mathrm{L} . \mathrm{d}$ and lipid productivity was $85 \mathrm{mg} / \mathrm{L} . \mathrm{d}$ while lipid content of $25 \%$ was obtained (Fan et al., 2012). In a similar work, after seeding C. vulgaris in a heterotrophic medium, the production culture was inoculated resulting in biomass and lipid productivities 1.48 and 1.42 times higher than those with photoautotrophic seed, respectively (Han et al., 2012). Biomass productivity in seed culture was 25.2 times higher than those obtained by photoautotrophy.

The two-stage strategy was applied to 5-liter bioreactors and cell productivity increased from $24 \times 10^{6}$ cell $/ \mathrm{mL}$.d under phototrophic condition to $178 \times 10^{6} \mathrm{cell} / \mathrm{mL}$.d under heterotrophic condition (Zheng et al., 2012). Although heterotrophic conditions improve biomass and lipid productivities significantly, this cultivation method does not appeal to algal industry too much as it requires supply of suitable feedstock such as lignocellulosic sugars which makes this technology costly (US DOE, 2010). Thus, autotrophic processes are still the main cultivation method particularly at large-scale operation.

In this study, as an alternative two-stage approach, a new strategy for improving biomass and lipid productivities of $C$. vulgaris based on a photoautotrophic cultivation scheme is proposed. This strategy relies on differing the inoculation (seed) culture from the production culture Unlike the conventional cultivation scheme in which algal cells are grown in a medium and then inoculated in the same medium in higher volumes (usually $5-10 \%$ vol), in this proposal algal cells are grown in a medium and then are harvested and inoculated in a different medium in higher volumes with different composition. It is worth mentioning that the choice of the two media and their compositions is a key factor.

\section{Materials and Methods}

\subsection{Algal Strain}

Chlorella $s p$. has been reported as the most suitable photoautotrophic microalgae for biofuel production due to its high productivity of fatty acids relevant to transesterification reaction (Hempel et al., 2012). These species are photosynthetic single cell green algae which are also used for body detox and human nutrition. Thereby, $C$. vulgaris was used as the working organism in this study. It was purchased from the Algae Culture Collection of Research Center for Basic and Applied Science at the University of Shahid Beheshti, Tehran, Iran.

\subsection{Materials}

Chemicals used in this study were all obtained from Merck Chemicals (Germany). Two media were used in this study. The Shuisheng-4 medium (SH4) included chemical components $(\mathrm{mg} / \mathrm{L}$ ) as follows (Qian et al., 2008): $\left(\mathrm{NH}_{4}\right)_{2} \mathrm{SO}_{4} 200 ; \mathrm{Ca}\left(\mathrm{H}_{2} \mathrm{PO}_{4}\right)_{2} \cdot \mathrm{H}_{2} \mathrm{O} 30 ; \mathrm{MgSO}_{4} .7 \mathrm{H}_{2} \mathrm{O} 80 ; \mathrm{NaHCO}_{3}$ 100; $\mathrm{KCl} 25 ; \mathrm{FeCl}_{3} 1.5 ; \mathrm{K}_{2} \mathrm{HPO}_{4} 10$; and $1 \mathrm{ml}$ elemental solution $(\mathrm{g} / \mathrm{L})$ containing: $\mathrm{H}_{3} \mathrm{BO}_{3} \quad 2.86 ; \mathrm{MnCl}_{2} .4 \mathrm{H}_{2} \mathrm{O} \quad 1.81 ; \mathrm{ZnSO}_{4} .7 \mathrm{H}_{2} \mathrm{O} \quad 0.222$ $\mathrm{Na}_{2} \mathrm{MoO}_{4} .2 \mathrm{H}_{2} \mathrm{O} 0.391 ; \mathrm{CuSO}_{4} .5 \mathrm{H}_{2} \mathrm{O} 0.079$. The $\mathrm{N} 8$ medium contained the following components $(\mathrm{mg} / \mathrm{L})$ (Mandalam and Palsson, 1998): $\mathrm{KNO}_{3}$ 1000; $\mathrm{KH}_{2} \mathrm{PO}_{4} 740 ; \mathrm{Na}_{2} \mathrm{HPO}_{4} .2 \mathrm{H}_{2} \mathrm{O}$ 260; $\mathrm{CaCl}_{2} .2 \mathrm{H}_{2} \mathrm{O}$ 13; FeEDTA 10; $\mathrm{MgSO}_{4} .7 \mathrm{H}_{2} \mathrm{O} 50$; dissolved in distilled water and $1 \mathrm{~mL}$ of elemental solution $(\mathrm{g} / \mathrm{L})$ including: $\quad \mathrm{MnCl}_{2} .4 \mathrm{H}_{2} \mathrm{O} \quad 12.98 ; \quad \mathrm{ZnSO}_{4} .7 \mathrm{H}_{2} \mathrm{O} \quad 3.2$ $\mathrm{CuSO}_{4} .5 \mathrm{H}_{2} \mathrm{O} 1.83 ; \mathrm{Al}_{2}\left(\mathrm{SO}_{4}\right)_{3} .18 \mathrm{H}_{2} \mathrm{O} 3.58$.

\subsection{Culture conditions}

Cells were grown in $500 \mathrm{ml}$ Erlenmeyer flasks containing $400 \mathrm{~mL}$ culture medium. The medium and flasks were sterilized in an autoclave for $15 \mathrm{~min}$ at $121{ }^{\circ} \mathrm{C}$ in order to prevent any contamination during stages of growth. Culture at $25^{\circ} \mathrm{C}$ was illuminated with cool white fluorescent lamps at an intensity of 3500 lux (equivalent to $40 \mu \mathrm{mol}$ photon $/ \mathrm{m}^{2} . \mathrm{s}$ ) in 16:8 h light-dark cycles. Air and pure $\mathrm{CO}_{2}$ (purity >99\%) were mixed with approximately $1 \% \mathrm{CO}_{2}$ and passed through a filter for sterilization and then bubbled into the solution. The aeration rate was measured using a rotameter (LZB-4WB), setting on $0.5 \mathrm{~L} / \mathrm{min}$. The $\mathrm{pH}$ of both media was adjusted to 7 using $\mathrm{NaOH}$ and $\mathrm{HCl}$ at the beginning and monitored throughout the experiment. To prepare inoculants, algal growth continued until the midst of exponential phase, i.e., approximately $44 \mathrm{~h}$ (including lag phase) for SH4 medium and approximately $80 \mathrm{~h}$ (including lag phase) for $\mathrm{N} 8$ medium. Next, a volume equivalent to $10 \%$ of the production medium was centrifuged at $4300 \mathrm{rpm}$ for $25 \mathrm{~min}$ to harvest cells. Then, the cell mass was washed twice with distilled water and re-suspended with production medium. In cases where inoculation and production media 
were the same, cell harvesting was ignored and inoculation was performed directly. In production medium, growth continued until late-exponential phase where optical density of the broth stayed nearly constant.

\subsection{Growth evaluation and biomass productivity}

After inoculation with $10 \%$ of the working volume of production medium, algal growth was determined by measuring optical density at $680 \mathrm{~nm}$ using a UNICO UV-VIS 2100 spectrophotometer (Unico Inc, Shanghai, China). One $\mathrm{mL}$ of sample was removed from culture broth in a sterile fashion and poured into a glass cuvette. Fresh medium was used as control. In order to confirm the relationship between optical density and growth, cell count was also performed. For each sample, $1 \mathrm{~mL}$ of algal suspension was removed through sampling tube and direct count was performed using Neubauer homocytometer under light microscope.

To determine the dry cell weight of the culture, $200 \mathrm{~mL}$ of culture broth was centrifuged at $4300 \mathrm{rpm}$ for $25 \mathrm{~min}$. Cells were washed twice with distilled water. Then, biomass was poured into an aluminum pre-weighted dish and dried at $80{ }^{\circ} \mathrm{C}$ for $24 \mathrm{~h}$. Biomass productivity was calculated as the ratio of dried biomass per volume per incubation time.

\subsection{Lipid content and productivity}

Algal broth at the late-exponential growth phase was divided into two aliquot parts. One part was utilized for cell dry weight measurement and the other part for lipid extraction. It was performed gravimetrically based on a method adapted from Bligh and Dyer (1959). Then lipid content was calculated as per the following equation (Eq. 1):

$C_{\text {Lipid }}=\frac{\text { weight of extracted lipid }}{\text { weight of dried biomass }} \times 100$

Lipid productivity is a factor related to lipid content and biomass productivity. It was calculated as follows (Eq. 2):

$P_{\text {Lipid }}(g / l . d)=\frac{C_{\text {Lipid }}(g / g) \times D C W(g / L)}{t(d)}$

Where $\mathrm{P}_{\text {Lipid }}$ is lipid productivity, $\mathrm{C}_{\text {Lipid }}$ is lipid content of cells, DCW is dry cell weight, and $t$ is the cultivation period (d).

\subsection{Scheme of experiments}

Experiments were conducted in four different schemes as stated in Table 1. $\mathrm{SH} 4$ as production medium inoculated with seed cells grown in $\mathrm{SH} 4$ as inoculation medium ( $\mathrm{SH} 4 / \mathrm{SH} 4), \mathrm{N} 8$ as production medium inoculated with seed cells grown in $\mathrm{N} 8$ as inoculation medium (N8/N8), SH4 as production medium inoculated with seed cells grown in $\mathrm{N} 8$ as inoculation medium (SH4/N8), and N8 as production medium inoculated with seed cells grown in $\mathrm{SH} 4$ as inoculation medium (N8/SH4). The two schemes in which production and inoculation media were the same were utilized as control for the evaluation of the other two schemes.

Table 1.

Scheme of experiments.

\begin{tabular}{lcccc}
\hline Cultivation scheme & $\begin{array}{c}\text { SH4 } \\
\text { inoculation } \\
\text { medium }\end{array}$ & $\begin{array}{c}\text { N8 } \\
\text { inoculation } \\
\text { medium }\end{array}$ & $\begin{array}{c}\text { SH4 } \\
\text { production } \\
\text { medium }\end{array}$ & $\begin{array}{c}\text { N8 } \\
\text { production } \\
\text { medium }\end{array}$ \\
\hline Scheme 1 (SH4/SH4) & $\times$ & $\times$ & $\times$ & \\
Scheme 2 (N8/N8) & & $\times$ & $\times$ & $\times$ \\
Scheme 3 (SH4/N8) & & & & \\
Scheme 4 (N8/SH4) & $\times$ & & & $\times$ \\
\hline
\end{tabular}

\section{Results and Discussion}

To investigate the effect of differing the inoculation medium from the production medium, two well-known culture media were adopted for growth of C. vulgaris in this study, i.e., N8 and SH4. The two media contained all the essential components required for the growth of $C$. vulgaris (Šoštarič et al., 2009). They were selected based on their quantitative elemental differences and their impacts on algal growth Comparison of the media indicated that in $\mathrm{N} 8$, nitrogen source is in the form of nitrate while in SH4, it is in the form of ammonium. Carbon dioxide is the only carbon source in N8, whereas carbon dioxide and sodium bicarbonate are two carbon sources contained in SH4. Nitrogen content of $\mathrm{N} 8$ is $9.93 \mathrm{mM}$ while it is $1.5 \mathrm{mM}$ in SH4 that is 6.6 folds less than that of $\mathrm{N} 8$ due to the higher concentration of $\mathrm{KNO}_{3}$ in $\mathrm{N} 8$ medium. Phosphorous content of the two media are significantly different as N8 has the phosphorous concentration of $6.8 \mathrm{mM}$ while SH4 contains 0.18 $\mathrm{mM}$ of elemental phosphorous. In terms of essential ions, the two selected media are approximately the same. Differences in carbon and nitrogen sources directly affect growth and lipid production which in turn change biomass and lipid productivities.

Under the four different cultivation schemes, the growth curves were initially investigated as presented in Figure 1. As seen in this figure, the time length of growth phases for two media were different. Using SH4 as production medium, the log phase took $88 \mathrm{~h}$ to complete while it took 160 $\mathrm{h}$ when $\mathrm{N} 8$ was used as production medium. In cases where production and inoculation media were different, optical density at the end of the growth phase reached 1.5 in N8 medium.

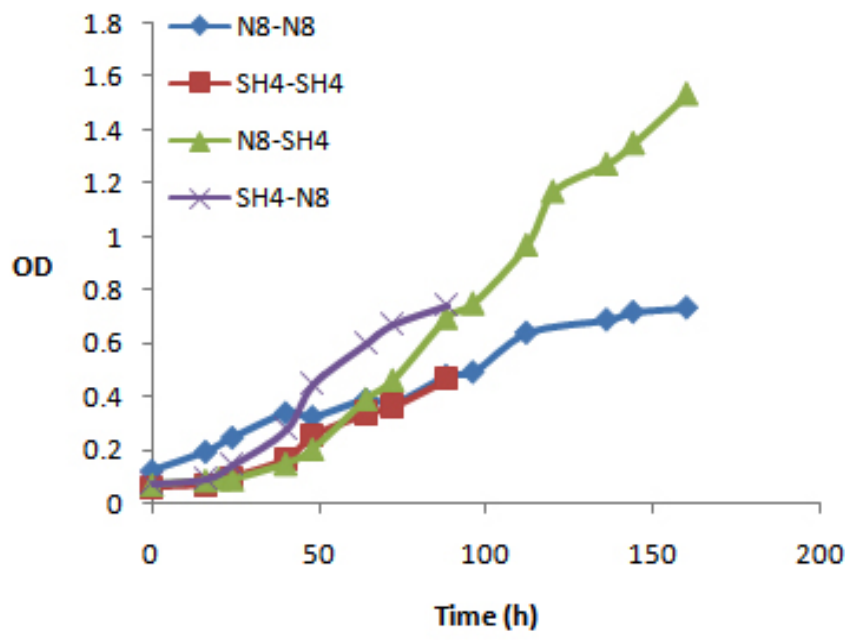

Fig.1. Growth curves of Chlorella vulgaris under different cultivation schemes.

The optical density reached 0.7 over the course of $160 \mathrm{~h}$ in N8 medium where inoculation and production media were the same. This showed a two-fold increase in optical density using a different inoculation culture. This was the case for $\mathrm{SH} 4$ production medium in which changing the inoculation medium from SH4 to N8 caused an increase in optical density from 0.45 to 0.7 in $88 \mathrm{~h}$. According to Table 2, biomass and lipid

Table 2.

Measured dry cell weights and lipid concentrations under different cultivation schemes.

\begin{tabular}{lcc}
\hline Cultivation scheme & Dry Cell Weight (mg/L) & Lipid Concentration (mg/L) \\
\hline SH4/SH4 & 150 & 45 \\
SH4/N8 & 350 & 65 \\
N8/N8 & 250 & 88 \\
N8/SH4 & 455 & 123 \\
\hline
\end{tabular}


productivities increased by $130 \%$ (from 150 to $350 \mathrm{mg} / \mathrm{L}$ ) and $44 \%$ (from 45 to $65 \mathrm{mg} / \mathrm{L}$ ), respectively, using SH4/N8 in comparison with SH4/SH4. In cases where $\mathrm{N} 8$ was the production medium (comparison between $\mathrm{N} 8 / \mathrm{N} 8$ and $\mathrm{N} 8 / \mathrm{SH} 4$ ) the biomass and lipid productivities increased by $82 \%$ (from 250 to $455 \mathrm{mg} / \mathrm{L}$ ) and $40 \%$ (from 88 to $123 \mathrm{mg} / \mathrm{L}$ ), respectively. These figures indicated that when the production medium was different from the inoculation medium, biomass and lipid productions boosted significantly.

Close examination of the observations revealed that for the enhancement of biomass production, differing the production medium from the inoculation medium was an effective strategy. Specifically SH4/N8 scheme was the best choice where biomass productivity increased by 2.3 folds. For lipid production enhancement, the same strategy was efficient in both SH4/N8 and N8/SH4 schemes and the lipid productivity was improved by $40 \%-44 \%$. Examination of the productivities shown in Table 3 indicated that in N8/N8 and $\mathrm{SH} 4 / \mathrm{SH} 4$ schemes of cultivation (identical production and inoculation media), lipid and biomass productivities were not significantly different; 13.2 vs. $12.3 \mathrm{mg} / \mathrm{L} . \mathrm{d}$ for lipid productivity, and $37.5 \mathrm{vs} .40 .9 \mathrm{mg} / \mathrm{L} . \mathrm{d}$ for biomass productivity, respectively.

Table 3.

Biomass and lipid productivities and lipid contents at different cultivation schemes for Chlorella vulgaris.

\begin{tabular}{lccc}
\hline $\begin{array}{c}\text { Cultivation } \\
\text { scheme }\end{array}$ & $\begin{array}{c}\text { Lipid Content } \\
\text { (\% dry weight biomass) }\end{array}$ & $\begin{array}{c}\text { Lipid Productivity } \\
\text { (mg/L.d) }\end{array}$ & $\begin{array}{c}\text { Biomass Productivity } \\
\text { (mg/L.d) }\end{array}$ \\
\hline SH4/SH4 & 30.0 & 12.3 & 40.9 \\
SH4/N8 & 18.6 & 17.7 & 95.4 \\
N8/N8 & 35.2 & 13.2 & 37.5 \\
N8/SH4 & 27.0 & 18.5 & 68.3 \\
\hline
\end{tabular}

In the two other schemes of cultivation, however, i.e., SH4/N8 and $\mathrm{N} 8 / \mathrm{SH} 4$, the lipid and biomass productivities increased remarkably as in SH4/N8, biomass productivity reached $95.4 \mathrm{mg} / \mathrm{L} . \mathrm{d}$ from base value of 40.9 $\mathrm{mg} / \mathrm{L} . \mathrm{d}$ and lipid productivity reached $17.7 \mathrm{mg} / \mathrm{L} . \mathrm{d}$ from the base value of $12.3 \mathrm{mg} / \mathrm{L} . \mathrm{d}$. In N8/SH4 scheme, biomass productivity reached $68.3 \mathrm{mg} / \mathrm{L} . \mathrm{d}$ from the base value of $37.5 \mathrm{mg} / \mathrm{L} . \mathrm{d}$ and lipid productivity reached 18.5 $\mathrm{mg} / \mathrm{L} . \mathrm{d}$ from base value of $13.2 \mathrm{mg} / \mathrm{L} . \mathrm{d}$. These figures confirmed that when the production and inoculation media were different in algal cultivation, biomass and lipid productivities were improved (Fig. 2).

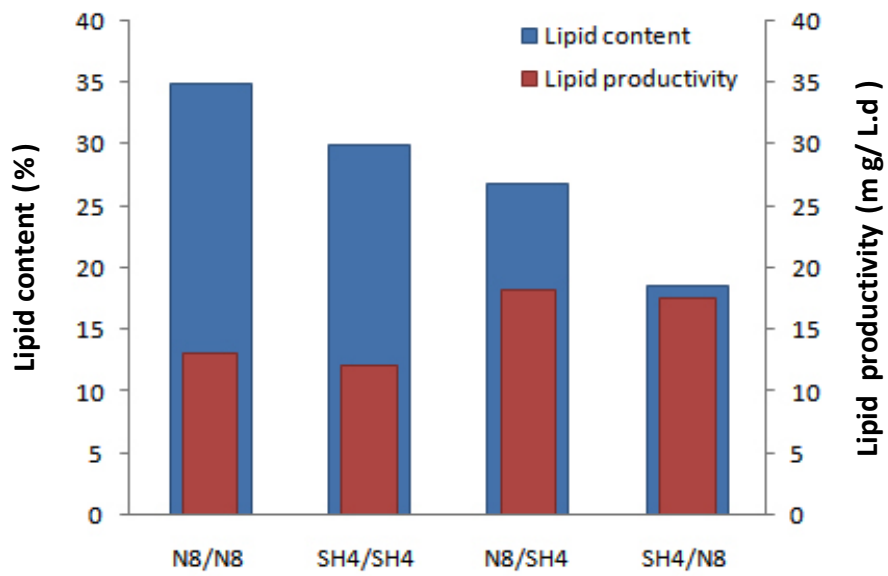

Fig.2. Comparison of lipid contents (\% dry weight biomass) and lipid productivities in four cultivation schemes.

The above-mentioned strategy, however, caused adverse effect on lipid content as seen in Figure 2. It was observed that lipid production increased while lipid content decreased. Theoretically, it was because increases in biomass production outweighed increases in lipid production and consequently lipid content decreased. In SH4/N8 culture, for example, "cumulative lipid production" increased by $44 \%$ from $45 \mathrm{mg} / \mathrm{L}$ to 65 $\mathrm{mg} / \mathrm{L}$ (see Table 2), whereas "lipid production per cell" decreased approximately by $5 \%$ compared with $\mathrm{SH} 4 / \mathrm{SH} 4$. The relationship between optical density and cell number was measured according to Equation 3:

$$
y=5.917 \times O D+0.203
$$

Where $y$ is the cell number when it is multiplied by $10^{6}$, and OD is optical density. Similarly, in N8/SH4 culture, "cumulative lipid production" increased by $40 \%$ from $88 \mathrm{mg} / \mathrm{L}$ to $123 \mathrm{mg} / \mathrm{L}$ (see Table 2) while "lipid production per cell" decreased approximately by $33 \%$ compared with N8/N8. Thus, increase in lipid production was due to the substantial increase in cell number and biomass rather than lipid production in a single cell. As a result, lipid content decreased while lipid productivity increased. The same observation was made in a study where growth under nutrient-rich conditions followed by cultivation under nitrogen starvation and controlled conditions of phosphate, light intensity, aeration, and carbon source was investigated (Mujtaba et al., 2012). In their study, lipid content decreased from 53\% under nutrient-rich to $43 \%$ under nitrogen starvation while lipid productivity increased from 77.1 $\mathrm{mg} / \mathrm{L} . \mathrm{d}$ to $77.8 \mathrm{mg} / \mathrm{L} . \mathrm{d}$. It should be noted that in both cultivation schemes i.e., SH4/N8 and N8/SH4 lipid content decreased and lipid productivity increased. This observation indicates that nitrogen concentration of the media could not be the sole reason for lipid production alteration. Other factors such as phosphorous content, chemical form of nitrogen, i.e., ammonium vs. nitrate, and metal elements may also contribute to the improvement of lipid productivity and reduction of lipid content.

Table 4 tabulates specific growth rates in the four cultivation schemes. As presented, in $\mathrm{SH} 4 / \mathrm{SH} 4$, specific growth rate was $45 \%$ higher than in $\mathrm{N} 8 / \mathrm{N} 8$ scheme $(0.0058 / \mathrm{h}$ in SH4/SH4 compared with $0.0040 / \mathrm{h}$ in N8/N8). This was while growth phase in N8 medium was twice longer than that in SH4 medium. Growth rate in each medium depends on both carbon and nitrogen sources. Carbon dioxide was the only carbon source in $\mathrm{N} 8$ medium which was bubbled into the medium with air. The $\mathrm{N} 8$ is a nutritious medium that contains more nitrogen than $\mathrm{SH} 4$ but in the form of nitrate $(1000 \mathrm{mg} / \mathrm{L}$ potassium nitrate in $\mathrm{N} 8$ vs. $200 \mathrm{mg} / \mathrm{L}$ ammonium sulphate in SH4). Basically, ammonium is the inorganic nitrogenous form that is easier to assimilate, since nitrate has to be reduced to ammonium prior to uptake (Richardson et al., 1969).

Table 4.

Specific growth rates of Chlorella vulgaris under four cultivation schemes.

\begin{tabular}{ll}
\hline Cultivation scheme & Specific growth rates $(/ \mathbf{h})$ \\
\hline SH4/SH4 & 0.0058 \\
SH4/N8 & 0.0083 \\
N8/N8 & 0.0040 \\
N8/SH4 & 0.0122 \\
\hline
\end{tabular}

This fact along with the continuous addition of carbon dioxide into the medium in excess with mass transfer limitation contributed to a longer growth phase in N8 (see Fig. 1). Suitable buffering capacity of N8 medium also might have contributed to the longer growth phase. The $\mathrm{pH}$ of the solution did not drop during growth phase $(\sim 7)$ indicating that all $\mathrm{CO}_{2}$ supplementation was converted to carbohydrate rather than proton. As shown in Figure 3, removing carbon dioxide from the process as the sole carbon source significantly reduced biomass production while $\mathrm{pH}$ did not change. This was the evidence that $\mathrm{CO}_{2}$ was predominantly fixed for biomass production. In SH4 medium two carbon sources were available, i.e., carbon dioxide and sodium bicarbonate. Concentration of bicarbonate 
Table 5.

Dry weight and lipid values per cell under four cultivation schemes.

\begin{tabular}{|c|c|c|c|c|c|}
\hline Production medium & Inoculation medium & OD & Cell number $(y)(\text { cell } / \mathbf{m L})^{*}$ & Lipid production per cell (mg Lipid/cell) & Dry weight per cell $\left(\mathrm{mg}\right.$ DCW/cell) ${ }^{* * *}$ \\
\hline \multirow{2}{*}{ SH4 } & SH4 & 0.45 & $2.8657 \times 10^{6}$ & $1.57 \times 10^{-8}$ & $5.23 \times 10^{-8}$ \\
\hline & N8 & 0.7 & $4.3449 \times 10^{6}$ & $1.50 \times 10^{-8}$ & $8.06 \times 10^{-8}$ \\
\hline \multirow{2}{*}{ N8 } & N8 & 0.7 & $4.3449 \times 10^{6}$ & $2.03 \times 10^{-8}$ & $5.75 \times 10^{-8}$ \\
\hline & SH4 & 1.5 & $9.0785 \times 10^{6}$ & $1.36 \times 10^{-8}$ & $5.01 \times 10^{-8}$ \\
\hline
\end{tabular}

* Cell number was calculated based on Equation 3.

** Calculated by dividing total lipid (Table 2) by cell number.

${ }^{* * *}$ Calculated by dividing total biomass (Table 2 ) by cell number.

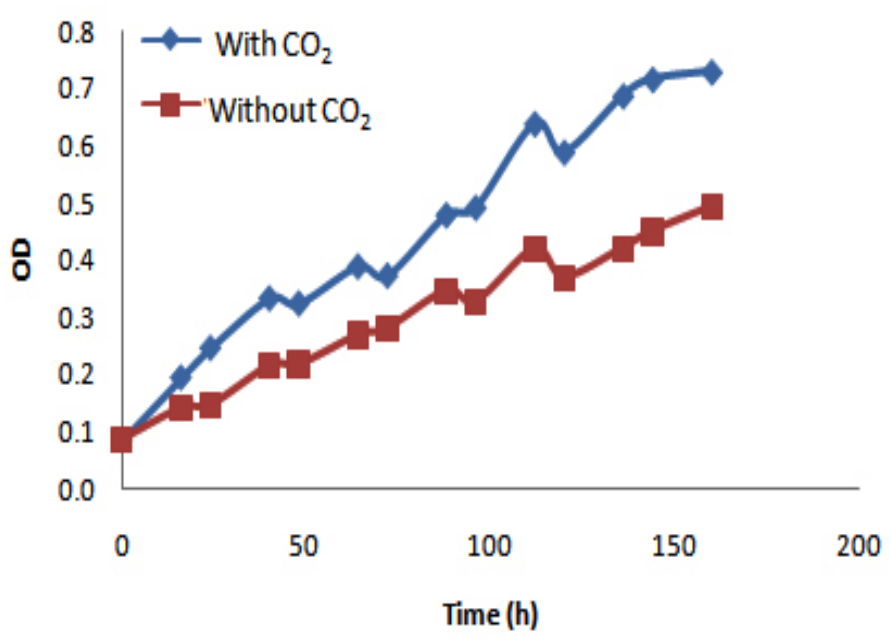

Fig.3. Growth curves of Chlorella vulgaris in $\mathrm{N} 8$ medium with/without $\mathrm{CO}_{2}$.

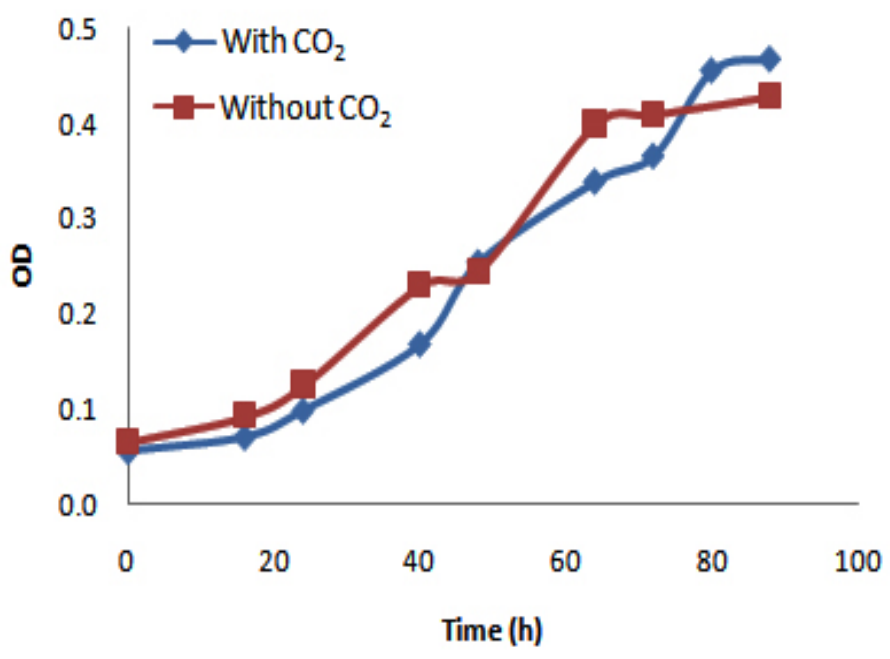

Fig.4. Growth curves of Chlorella vulgaris in $\mathrm{SH} 4$ medium with/without $\mathrm{CO}_{2}$. in this solution was 100 times more than that of $\mathrm{CO}_{2}$ while $\mathrm{pH}$ was the final factor that determined which carbon source was consumed in the solution.

As seen in Figure 4, removing $\mathrm{CO}_{2}$ from the medium did not noticeably change biomass concentration at the end of the growth phase due to the presence of bicarbonate but the growth levelled off at $65 \mathrm{~h}$. However, the presence of $\mathrm{CO}_{2}$ in the medium contributed to longer growth phase to $88 \mathrm{~h}$ with approximately the same biomass concentration.

Inoculation of $\mathrm{N} 8$ production medium with seed cells grown in $\mathrm{SH} 4$ significantly increased growth rate from $0.0040 / \mathrm{h}$ to $0.0122 / \mathrm{h}$ as well as biomass and lipid productivities. Cells already grown in SH4 were introduced in the high nitrogen content and nutritious N8 medium in which underwent a metabolic stress. This metabolic stress enforced protein and biomass production pathway, i.e., route 1 in Figure 5, resulting in higher biomass productivity while lipid production was suppressed due to higher nitrogen concentration. More biomass production compensated lower lipid content and consequently lipid productivity increased. It is indicated that under nutrient limitation stress condition there is a negative correlation between growth rate and lipid content (Roleda et al., 2013). Inoculation of SH4 medium with seed cells grown in N8 put cells in an environment with low nitrogen but in form of ammonium that was easier to uptake (Von Ruckert and Giani, 2004). This situation increased biomass production because of the change in metabolism and improved specific growth rate from $0.0058 / \mathrm{h}$ to $0.0083 / \mathrm{h}$ Lipid production was inhibited in the presence of ammonia and metabolism was conducted toward biomass production through route 1 in Figure 5. Thus, biomass concentration reached higher values in a shorter period of time (approximately $88 \mathrm{~h}$ ) resulting in higher lipid and biomass productivities due to higher cell concentration as reported in Table 3 . During this period, biomass productivity underwent a 2.3 -fold increase. The drop of $\mathrm{pH}$ from 7 to approximately 3.3 after this time, was due to the accumulation of protons as a result of assimilation of ammonium.

Close examination of changes in cell number as well as lipid and dry weight content of the cells in Table 5 revealed that the best cultivation scheme for lipid productivity and specifically biomass productivity enhancement was SH4/N8 scheme. As seen in Table 5, in cases where SH4 was the production medium, inoculants from N8 culture not only increased the cell number by $52 \%$, but also increased "dry weight per cell" as high as $54 \%$ compared with inoculants from SH4 culture. This alteration led to a 2.33-fold improvement in biomass productivity. Simultaneously, inoculants from N8 increased lipid productivity by $44 \%$ compared with inoculants from SH4, "lipid production per cell' decreased by $5 \%$ though. Interestingly, in cases where N8 was the production medium, inoculants from SH4 culture increased the cell number by $109 \%$, while, both "lipid production per cell" and "dry weight per cell" decreased by $33 \%$ and $13 \%$, respectively, compared with inoculants from N8 culture. Combination of these changes resulted in $82 \%$ improvement in biomass productivity as well as $40 \%$ improvement in lipid productivity.

Overall, this analysis indicated that inoculation of a medium such as SH4 or N8 with seed cells from another medium improved biomass and lipid productivities. The choice of inoculation medium, however, was 


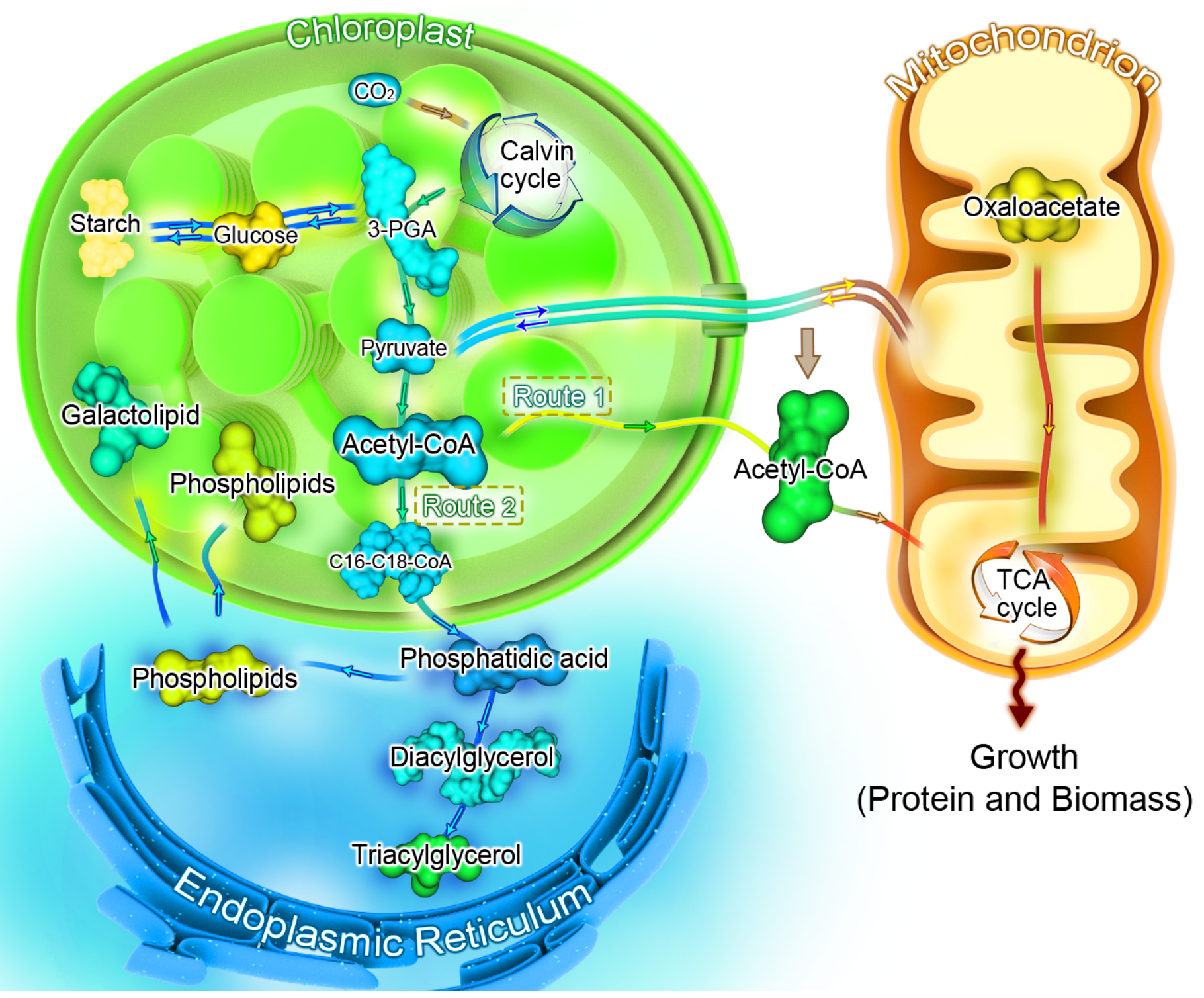

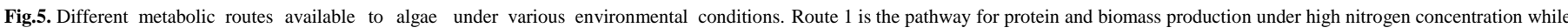
Route 2 is the pathway for lipid synthesis under low nitrogen concentration.

shown to be important as the SH4/N8 cultivation scheme improved biomass and lipid productivities to a higher extent compared with the N8/SH4 cultivation scheme. This method of algal cultivation has potential to be applied at commercial scale. On one hand, this technique is all about improvement of biomass and lipid productivities and it should be noted that lipid productivity is a more indicative index of total lipid production than lipid content from the commercial standpoint (Griffiths and Harrison, 2009). On the other hand, it imposes no additional cost on the large-scale operation expenses while the extent of improvement is significant in terms of lipid productivity (40-44\%) and specifically biomass productivity (2.3 folds). Compared with the other two-stage approaches that provide stress conditions to increase lipid and biomass production, this technique may be too appealing to the industry to be ignored.

\section{Conclusions}

Production of microalgae $C$. vulgaris in a culture medium that was inoculated with cells grown in a different medium was proved to be an effective strategy to improve biomass and lipid productivities. This strategy was employed using two well-known algal media, i.e., SH4 and $\mathrm{N} 8$ and the results indicated that in $\mathrm{SH} 4$ production medium inoculated with cells grown in $\mathrm{N} 8$, biomass productivity increased by 2.3 -folds and lipid productivity increased by $44 \%$ compared with the case where $\mathrm{SH} 4$ production medium inoculated with cells grown in the same medium. The extent of improvement in biomass and lipid productivities was remarkable with regard to the fact that no major changes were needed to be applied to a conventional photoautotrophic algal cultivation. Other algal media and 
their combinations for cultivation need to be examined for such a potential productivity improvement.

\section{Acknowledgements}

This work was financially supported by Graduate Students Research Fund at Ferdowsi University of Mashhad, Iran. Grant No. 11828. The authors declare no conflict of interest financially and personally.

\section{References}

[1] Bligh, E.G., Dyer, W.J., 1959. A rapid method of total lipid extraction and purification. Can. J. Biochem. Phys. 37, 911-917.

[2] Carlsson, A.S., van Beilen, J.B., Moller, R. Clayton, D., 2007. Microand macro-algae: utility for industrial applications: Outputs from the EPOBIO Project, CPL Press, UK.

[3] Chu, F.F., Chu, P.N., Cai, P.J., Li, W.W., Lam, P.K.S., Zeng, R.J., 2013. Phosphorous plays an important role in enhancing biodiesel productivity of Chlorella vulgaris under nitrogen deficiency. Bioresour. Technol. 134, 341-346.

[4] Converti, A., Cassaza, A.A., Ortiz, E.Y., Perego, P., Del Borghi, M., 2009. Effect of temperature and nitrogen concentration on the growth and lipid content of Nannochloropsis oculata and Chlorella vulgaris for biodiesel production. Chem. Process. Eng. Process Intensif. 48, 11461151.

[5] Fan, J., Huang, J., Li, Y., Han, F., Wang, J., Li, X., Wang, W., Li, S., 2012. Sequential heterotrophy-dilution-photoinduction cultivation for efficient microalgal biomass and lipid production. Bioresour. Technol. $112,206-211$

[6] Griffiths, M.J., Harrison, S.T.L., 2009. Lipid productivity as a key characteristic for choosing algal species for biodiesel production. J. Appl. Phycol. 21, 493-507.

[7] Han, F., Huang, J., Li, Y., Wang, W., Wang, J., Fan, J., Shen, G., 2012. Enhancement of microalgal biomass and lipid productivities by a model of photoautotrophic culture with heterotrophic cells as seed. Bioresour. Technol. 118, 431-437

[8] Hempel, N., Petrick, I., Behrendt, F., 2012. Biomass productivity and productivity of fatty acids and amino acids of microalgae strains as key characteristics of suitability for biodiesel production. J. Appl. Phycol. 24, 1407-1418

[9] Hu, H., Gao, K., 2006. Response of growth and fatty acid compositions of Nannochloropsis sp. to environmental factors under elevated $\mathrm{CO}_{2}$ concentration. J. Biotechnol. Lett. 28, 987-992.

[10] Illman, A.M., Scragg, A.H., Shales, S.W., 2000. Increase in Chlorella strains calorific values when grown in low nitrogen medium. J. Enzyme Microb. Technol. 27, 631-635.

[11] Jiang, Y., Yoshida, T., Quigg, A., 2012. Photosynthetic performance, lipid production and biomass composition in response to nitrogen limitation in marine microalgae. Plant Physiol. Biochem. 54, 70-77.

[12] Lee, K., Lee, C.G., 2001. Effect of light/dark cycles on wastewater treatments by microalgae. Biotechnol. Bioprocess Eng. 6, 194-199.

[13] Liang, Y., Sarkany, N., Cui, Y., 2009. Biomass and lipid productivities of Chlorella vulgaris under autotrophic, heterotrophic and mixotrophic growth conditions. Biotechnol. Lett. 31, 1043-1049.

[14] Liu, Z.Y., Wang, G.C., Zhao, B.C., 2008. Effect of iron on growth and lipid accumulation in Chlorella vulgaris. Bioresource. Technol. 99, 4717-4722.

[15] Lv, J.M., Cheng, L.H., Xu, X.H., Zhang, L., Chen, H.L., 2010 Enhanced lipid production of Chlorella vulgaris by adjustment of cultivation condition. Bioresour. Technol. 101, 6797-6804.

[16] Mandalam, R.K., Palsson, B.O., 1998. Elemental balancing of biomass and medium composition enhances growth capacity in high-density Chlorella vulgaris cultures. Biotechnol. Bioeng. 59, 605-611.

[17] Mata, T.M., Martins, A.A., Caetano, N.S., 2010. Microalgae for biodiesel production and other applications: a review. Renew. Sust. Energy Rev. 14, 217-232

[18] Miao, X., Wu, Q., 2006. Biodiesel production from heterotrophic microalgal oil. Bioresource. Technol. 97, 841-846.
[19] Mujtaba, G., Choi, W., Lee, C.G., Lee, K., 2012. Lipid production by Chlorella vulgaris after a shift from nutrient-rich to nitrogen starvation conditions. Bioresour. Technol. 123, 279-283.

[20] Nigam, S., Rai, M.P., Sharma, R., 2011. Effect of nitrogen on growth and lipid content of Chlorella pyrenoidosa. Am. J. Biochem. Biotechnol. 7(3), 124-129

[21] Pittman, J.K., Dean, A.P., Osundeko, O., 2011. The potential of sustainable algal biofuel production using wastewater resources. Bioresour. Technol. 102, 17-25.

[22] Qian, H., Chen, W., Sheng, G.D., Xu, X., Liu, W., Fu, Z., 2008 Effects of glufosinate on antioxidant enzymes, subcellular structure, and gene expression in the unicellular green algae Chlorella vulgaris. Aquat. Toxicol. 88, 301-307.

[23] Razon, L.F., Raymond, R.T., 2011. Net energy analysis of the production of biodiesel and biogas from the microalgae Haematococcus pluvialis and Nannochloropsis. Appl. Energy. 88 3507-3514.

[24] Richardson, B., Orcutt, D.M., Schwertner, H.A., Martinez, C.L., Wickline, H.E., 1969. Effects of nitrogen limitation on the growth and composition of unicellular algae in continuous culture. Appl. Environ. Microbiol. 18, 245-250.

[25] Roleda, M.Y., Slocombe, S.P., Leakey, R.J.G., Day, J.G., Bell, E.M., Stanley, M.S., 2013. Effects of temperature and nutrient regimes on biomass and lipid production by six oleaginous microalgae in batch culture employing a two-phase cultivation strategy. Bioresour. Technol. 129, 439-449.

[26] Sheehan, J., Dunahay, T., Benemann, J., Roessler, P., 1998. A look back at the U.S. Department of Energy's Aquatic Species Program: biodiesel from algae. National Renewable Energy Laboratory, Golden, CO, Report NREL/TP-580.

[27] Singh, P., Guldhe, A., Kumari, S., Rawat, I., Bux, F., 2015. Investigation of combined effect of nitrogen, phosphorous and iron on lipid productivity of microalgae Ankistrodesmus falcatus KJ671624 using response surface methodology. Biochem. Eng. J. 94, 22-29.

[28] Šoštarič, M., Golob, J., Bricelj, M., Klinar, D., Pivec, A., 2009 Studies on the growth of Chlorella vulgaris in culture media with different carbon sources. Chem. Biochem. Eng. Q. 23(4), 471-477.

[29] Tang, H., Abunasser, N., Garcia, M.E.D., Chen, M., Simon Ng, K.Y., Salley, S.O., 2011. Potential of microalgae oil from Dunaliella tertiolecta as a feedstock for biodiesel. Appl. Energy. 88, 33243330.

[30] Tran, H.L., Kwon, J.S., Kim, Z.H., Oh, Y., Lee, C.G., 2010. Statistical optimization of culture media for growth and lipid production of Botryococcus braunii LB572. Biotechnol. Bioprocess Eng. 15, 277-284.

[31] US DOE, 2010. National algal biofuels technology roadmap. US Department of Energy, Office of Energy Efficiency and Renewable Energy, Biomass Program.

[32] Uslu, L., Isik, O., Koc, K., Goksan, T., 2011. The effects of nitrogen deficiencies on the lipid and protein contents of Spirulina platensis. Afr. J. Biotechnol. 10, 386-389.

[33] Von Ruckert, G., Giani, A., 2004. Effect of nitrate and ammonium on the growth and protein concentration of Microcystis viridis Lemmermann (Cyanobacteria). Braz. J. Bot. 27, 325-331

[34] Widjaja, A., Chien, C.C., Ju, Y.H., 2009. Study of increasing lipid production from fresh water microalgae Chlorella vulgaris. J. Taiwan. Inst. Chem. Eng. 40, 13-20.

[35] Yusof, Y.A.M., Basari, J.M.H., Mukti, N.A., Sabuddin, R., Muda, A.R., Sulaiman, S., Makpol, S., Wan Ngah, W.Z., 2011. Fatty acids composition of microalgae Chlorella vulgaris can be modulated by varying carbon dioxide concentration in outdoor culture. Afr. J. Biotechnol. 10, 13536-13542.

[36] Zheng, Y., Chi, Z., Lucker, B., Chen, S., 2012. Two-stage heterotrophic and phototrophic culture strategy for algal biomass and lipid production. Bioresour. Technol. 103, 484-488. 